\title{
Failure Analysis of Ceramic Substrates Used in High Power IGBT Modules
}

\author{
Zenjebil Jouini, Zarel Valdez-Nava, David Malec \\ LAPLACE, Université de Toulouse, CNRS, INPT, UPS, Toulouse, France \\ Email: jouini@laplace.univ-tlse.fr
}

How to cite this paper: Jouini, Z., ValdezNava, Z. and Malec, D. (2016) Failure Analysis of Ceramic Substrates Used in High Power IGBT Modules. Engineering, 8, 561-571. http://dx.doi.org/10.4236/eng.2016.89052

Received: May 20, 2016

Accepted: August 29, 2016

Published: September 2, 2016

Copyright $\odot 2016$ by authors and Scientific Research Publishing Inc. This work is licensed under the Creative Commons Attribution International License (CC BY 4.0).

http://creativecommons.org/licenses/by/4.0/

\begin{abstract}
High voltage power modules are used in numerous applications to build high power converters. Technically, these modules are made of different materials and among them, dielectric materials are organic and inorganic. Organic insulators (gels) are used to avoid corona discharges in the vicinity of connecting wires and high voltage dies (diodes and transistors) and to protect them from moisture and contaminants. Inorganic insulators (ceramic substrates) are used to insulate the high voltage which dies from the grounded elements and to transfer heat to the heat sink. Despite being used since the late 90s, there is a lack of fundamental knowledge about the electrical properties of these substrates. Consequently, manufacturers tend to assure the reliability by over sizing them. As there are no clear rules for how to do that, failures occur, leading to the converter shutdown. The aim of this study is to bring new information about the understanding of the dielectric strength of ceramic materials used in these modules. We have focused our work on the correlation between the mechanical and the dielectric properties of ceramics by using relevant experiments. We provide new information about the impact of existing cracks on the ceramic dielectric failure, according to the electromechanical breakdown model. Our conclusions bring crucial information about the precautions to be taken during manufacturing and implementation of these substrates in power modules to reduce the likelihood of the particular causes of failure.
\end{abstract}

\section{Keywords}

High Voltage Power Module, Ceramic Substrate, Dielectric Strength, Electro-Mechanical Breakdown

\section{Introduction}

\subsection{Modules and Ceramics}

Currently used high voltage power electronics systems are based on an elementary 
brick called "power module", where the active semiconductors are packaged. Inside this assembly, one finds different materials, whose functions are to assure the interconnection, the insulation and the heat exchange between the semiconductor and its environment. A simplified schema of a power module is shown in Figure 1.

The interconnection of the semiconductors and their insulation from the heat sink (connected to the ground) is mainly achieved by a single element called "substrate". Furthermore, one of its main functions is to warrant the electrical insulation between the semiconductors and their environment. Moreover, it must also ensure the evacuation of the heat generated by the semiconductors. Theses substrates are composed of metallic conductors and an insulating material. When the thermal requirements are high, ceramics are the first choice due to their high thermal conductivity $(>20 \mathrm{~W} / \mathrm{m} \cdot \mathrm{K})$. Different ceramic materials are used for substrates elaboration (e.g. $\mathrm{BeO}, \mathrm{Si}_{3} \mathrm{~N}_{4}, \mathrm{AlN}$ ) [1]. Different technologies allow joining the ceramic to a conducting metal, such as DBC (Direct Copper Bonding) or AMB (Active Metal Brazing). Reliability of the substrate is often related to the mechanical properties of the ceramic material coupled with the metal being used. With the development of the new wide bandgap semiconductors, such as $\mathrm{SiC}$ or $\mathrm{GaN}$, higher voltages along with higher current densities could potentially increase the insulating requirements imposed on the ceramic materials inside the substrates [2].

Different causes may lead to the module failure:

- dies failures [3] [4],

- bonding wires cut [5]-[8],

- solder joints delamination [9]-[12],

- encapsulation gel dielectric breakdown [13]-[15],

- substrate dielectric breakdown [16] [17].

The design and the choice of the substrate depend on several parameters, such as the mechanical properties of the metal-ceramic assembly, the thermal properties of the ceramic and its electrical insulating capability. As a basic principle, if the ceramic material is capable of reaching very high operating voltages, its thickness can be reduced, hence decreasing the thermal resistance along the heat evacuation path. The dielectric

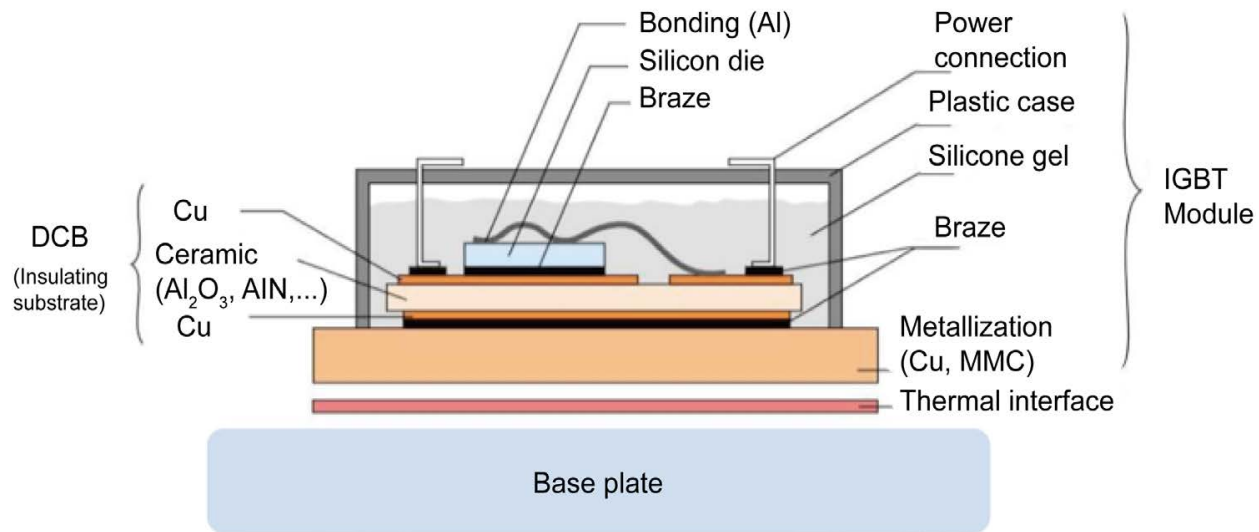

Figure 1. Schematic drawing of a power module used to package semiconductor dies. 
strength is then a critical dimensioning parameter for the ceramic materials used in these power modules. Despite this, there is little available information concerning the relationship among the processing parameters, the ceramic microstructure and the dielectric breakdown field.

For ceramics, as for the other solid materials, the origin of the dielectric breakdown will highly depend on the thermodynamic conditions at which the dielectric breakdown occurs. For example, alumina and other ceramics used at very high temperatures $\left(>600^{\circ} \mathrm{C}\right)$, will show a thermal breakdown due to its high electrical conductivity [18]. Nevertheless, if we consider much lower temperatures of currently used modules (i.e., $135^{\circ} \mathrm{C}$ for Si dies), the substrates are confronted to lower operating temperatures. At these temperatures, thermal breakdown is already excluded as a possible mechanism.

Previous works pointed out that the electric breakdown of ceramics at room temperature could be strongly linked to their mechanical properties [19]. It is assumed that the electric field induces the propagation of the pre-existing cracks within the ceramic material. This assumption has been studied under a high electric field (short term breakdown) [20] or under a moderate field (aging studies) [21].

This hypothesis is described in the literature as an "electromechanical dielectric breakdown", based on the analogy of the theory with mechanical breakdown in brittle materials. In such a model, the pre-existing cracks or defects are propagated under the influence of the applied electric field until the final breakdown (Figure 2).

One of the main challenges to verify this hypothesis is to control the size of the initial defect or crack in the ceramic. Previous attempts included the use of ceramics sintered at different temperatures, with different microstructures or with different compositions [17] [22] [23]. This could induce a change in the intrinsic dielectric breakdown strength of the studied material, potentially biasing the results.

In this work, we will employ a mechanical pre-stress in order to produce different defect sizes inside the ceramic, without modifying the chemical composition of its microstructure. Alumina $\left(\mathrm{Al}_{2} \mathrm{O}_{3}\right)$ substrates, largely used in power modules, have been selected as the representative samples. Results will be confronted with the electromechanical breakdown model. Finally, our experiments will be analyzed to extract the recommendations on the design rules that could be taken into account in the ceramic substrates manufacturing process.

\subsection{Origin of the Dielectric Breakdown}

The purpose of this work is to understand the mechanisms of the electric breakdown of the ceramics used in the elaboration of substrates for power electronics.

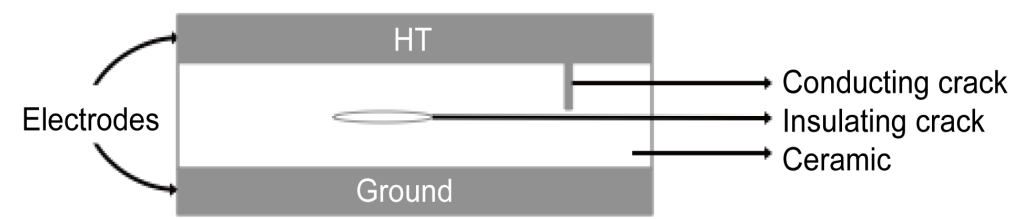

Figure 2. General model for an electromechanical breakdown (inspired by Griffith's proposal). 
The dielectric breakdown of solids can be classified into three types, depending on the underlying physical phenomena: 1) of electronic origin (electronic avalanche or field or intrinsic effect), 2) of thermal origin, which dissipates the heat caused by the current of conduction or dielectric losses and 3) electromechanical origin explaining the inability of the material to withstand mechanical stresses induced by the electric field.

Generally speaking, these mechanisms are not independent and may interact until the final breakdown. It is therefore often difficult to determine and isolate one physical phenomenon responsible for the dielectric breakdown.

\section{Experimental Procedure}

\subsection{Ceramic Material under Study}

The chosen ceramic materials are industrially available alumina $\left(\mathrm{Al}_{2} \mathrm{O}_{3}\right)$ plates (thickness $635 \mu \mathrm{m}$ ), typically used DBC ceramic substrates for power modules. The purity of the alumina is reported as $96 \%$; with $4 \%$ of other sintering additives and impurities (mainly $\mathrm{Si}, \mathrm{B}, \mathrm{Mg}, \mathrm{Ca}$ ). The alumina has an average grain size of $4 \mu \mathrm{m}$ observed by scanning electron microscopy (Figure 3 ).

In order to limit the dispersion due to the processing conditions, we paid special attention to make sure that the alumina plates, originated from the same manufacturer, were extracted from the same batch number. Random sampling (18 tests) showed that the dielectric breakdown of the analyzed batch was $21 \mathrm{kV} / \mathrm{mm}$ (at room temperature). Breakdown experiments are detailed in section 2.3. Alumina plates were then cut out from the as-received dimension of $115 \times 115 \mathrm{~mm}$ to smaller plates of $38 \times 38 \mathrm{~mm}$ by laser cutting. After laser cutting, the dielectric breakdown field in the central part of the alumina remained unchanged.

\subsection{Mechanical Prestress}

In the electromechanical breakdown model, the dielectric breakdown strength is limited due to the presence of defects, following the analogy with the Griffith's proposal

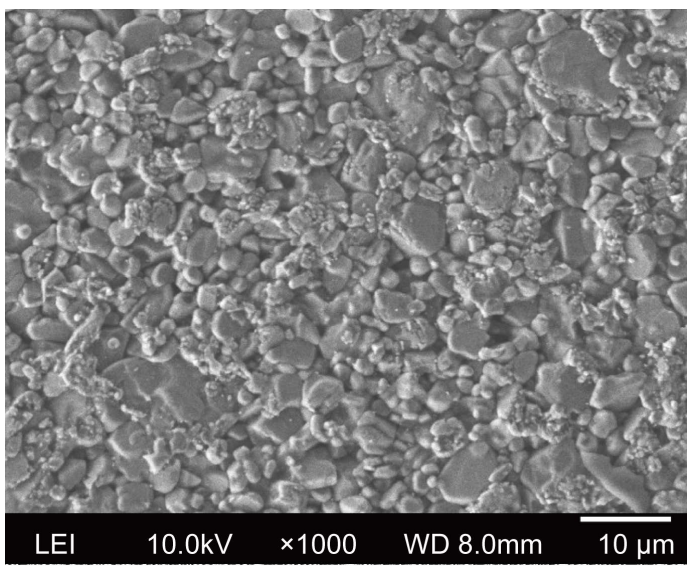

Figure 3. Microstructure of the alumina under study. 
for mechanical breakdown. In its most basic form, these defects could be cracks, crevices or any mechanical discontinuities inside the bulk of the material. As stated previously, in order to avoid any chemical or microstructural modification, we applied a mechanical pre-stress to our alumina samples. Mechanical stresses can be applied by the compression, traction or flexion. Considering the high compressive strength of alumina, we decided to apply a flexion force. One of the simplest configurations to apply a flexural stress is by a 3-point bending test (Figure 4a). We assume that in this configuration cracks will be created at the maximum tensile stress region of the 3-point bending configuration, i.e. in the center region where the upper ram applies the force (Figure $4 \mathrm{~b}$ ). In these conditions, initial cracks will be propagated or new ones will be formed. The large difference in the compressive (2000 GPa) and tensile (200 GPa) strength of alumina will favor the formation of the cracks on the tensile region of the cross-section of the ceramic material (opposite to the contact point of the upper ram).

Total applied mechanical stress is a function of the sample dimensions and test bench geometry as follows:

$$
\sigma_{m}=\frac{12 M l d}{B h^{3}} ; M=\frac{F l^{2}}{2}
$$

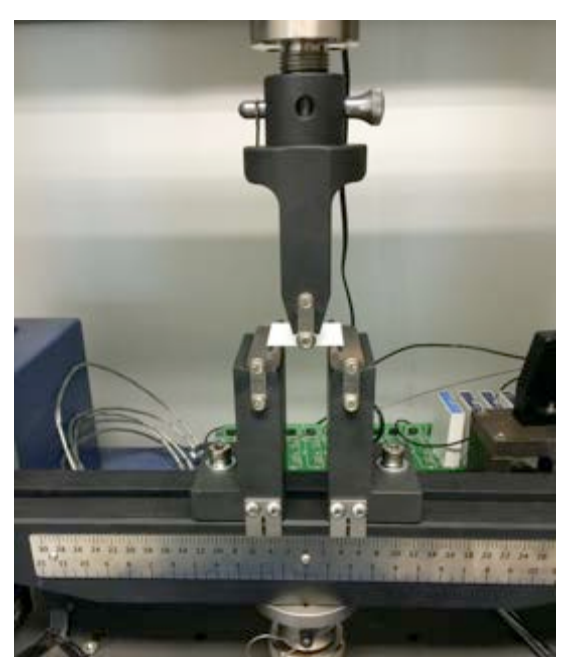

(a)
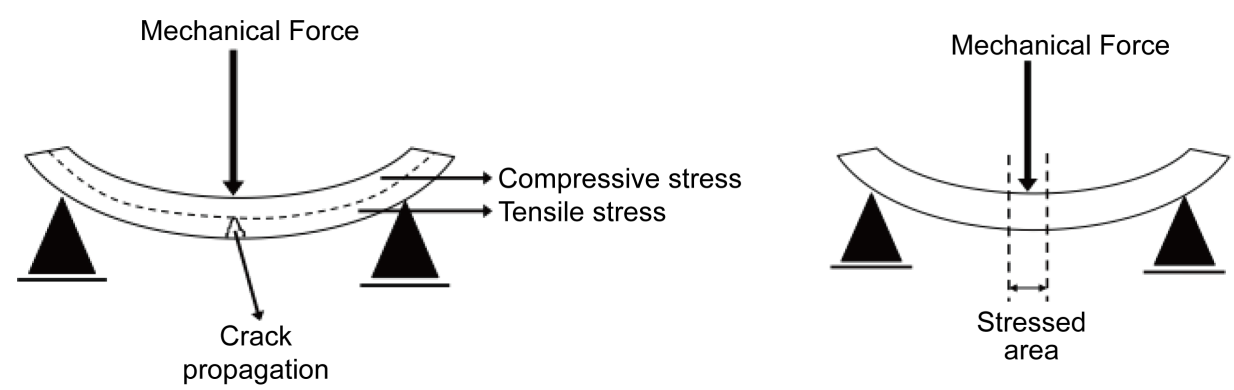

(b)

Figure 4. (a) 3-point bending test bench used for applying a mechanical prestress on alumina plates, (b) tensile stress is created at the bottom part of the alumina plate. 
where $M$ is the moment bending, $l$ is the length of the support (outer) span, $F$ is the load (force) at the fracture point, $B$ is the base of the sample, $h$ is the effective thickness of the sample.

Since the formation of a crack or a network of cracks reduces the effective section of the alumina plates, if a constant force is applied, the real stress will increase as the crack(s) propagate(s) along the thickness of the material. The final crack dimension will be then related to its initial size, the applied force and the time spent under such a force. A series of tests were performed to determine the mechanical prestress conditions (force and application time) prior to electrical breakdown. The characteristic of the time-to-breakdown (mechanical) vs. the applied force is shown in Figure 5.

The maximum force possible to apply is $180 \mathrm{~N}$, which corresponds to the mechanical flexural strength of the studied alumina. An attempt was made to study the full range of applicable forces. However, samples needed to be transported from the mechanical test bench to the dielectric breakdown test bench, and for high values of the force $(>100 \mathrm{~N})$ even a short time of prestress could break the samples during their manipulation. For this study, samples were prestressed from $20 \mathrm{~N}$ to $80 \mathrm{~N}$, applying the force for 1 minute. This allowed the samples to be handled without the risk of breaking them. Samples were marked with a felt-tip pen to identify the region where the force ram was in contact.

\subsection{Dielectric Breakdown of Prestressed Alumina}

The dielectric strength measurements were performed in a plane-tip configuration. The tip in contact with the sample is a cylinder of a diameter of $1 \mathrm{~mm}$. An AC generator regulated by an autotransformer was controlled with a step motor to modulate the ramp of the amplitude of the applied voltage. Short term dielectric breakdown values were obtained with a ramp of $1.6 \mathrm{kV} / \mathrm{s}$. Dielectric breakdown detection and voltage cutoff is triggered by the rapid increase in the current. Samples are immerged in a dielectric fluid (Galden HT270) to avoid surface flashovers. The felt-tip pen line helped to

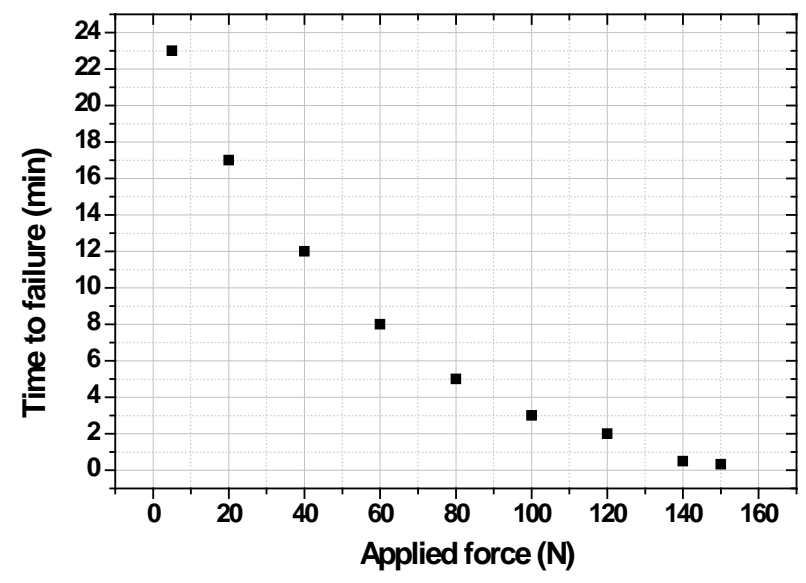

Figure 5. Time-to-breakdown (mechanical) vs. applied mechanical force for $635 \mu \mathrm{m}$ alumina plates under study. 
position the tip in the region of the maximum stress in order to induce dielectric breakdown in this zone. The results of the dielectric breakdown values are plotted against the mechanical prestress for each sample.

A scheme of the followed procedure is shown in Figure 6.

\section{Results and Discussion}

Figure 7 shows the ceramic plates after the dielectric breakdown was performed. The size of the alumina plates allowed for 3 to 4 dielectric breakdown tests per sample.

When plotting the results in a Weibull chart we can easily identify that the dispersion of the results obtained for the prestressed samples are significantly higher than the ones obtained for the un-stressed sample (0 N) (Figure 8).

To better observe the impact of the mechanical prestress, only the $\alpha$ parameter (cumulative probability of $63.2 \%$ ) of the dielectric breakdown extracted from a two-coefficient Weibull distribution was plotted (Figure 9).

Despite the significant dispersion of the values, we can observe a decrease in the dielectric strength of the alumina when it is mechanically prestress. The decrease on the $\alpha$ parameter is more important as the mechanical prestress value increases. One of the reasons for the large dispersion of the values of $E_{b r}$ could originate from our inability to

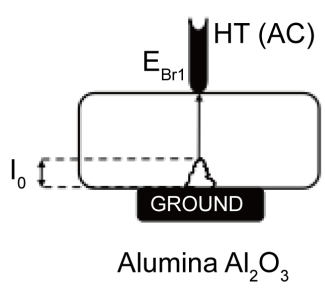

(a)

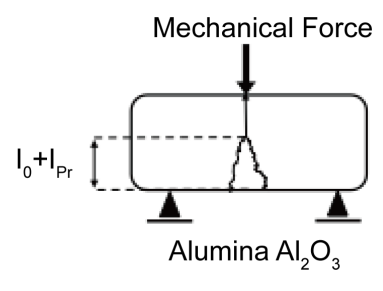

(b)

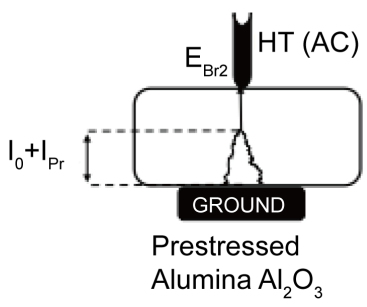

(c)

Figure 6. (a) Reference sample with an initial crack length $l_{0}$, (b) mechanical prestress that increases the crack length inside the ceramic, total length is $l_{0}+l_{m}$, (c) dielectric breakdown of the prestressed ceramic.
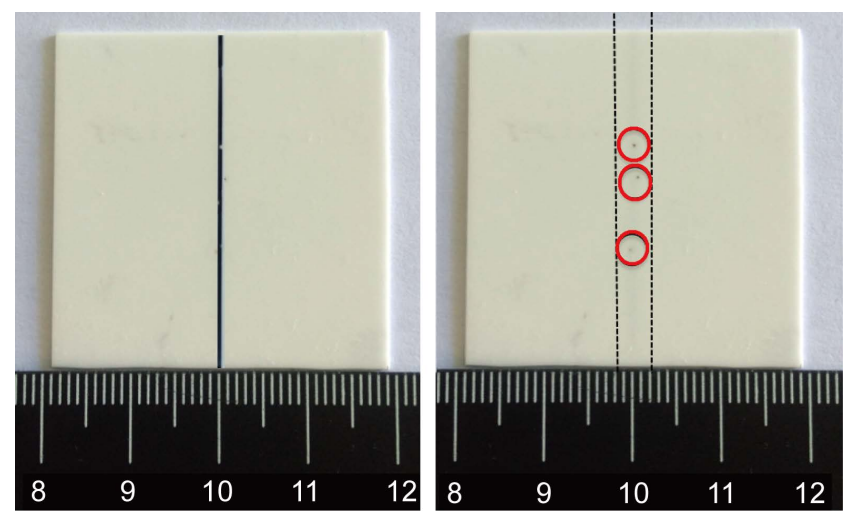

Figure 7. Dielectrically broken down alumina sample. Top surface was submitted to compression (black line, felt-tip pen) and bottom suface under tensile stress. Red circles indicate the rupture channel exit points on the surface of the alumina. 


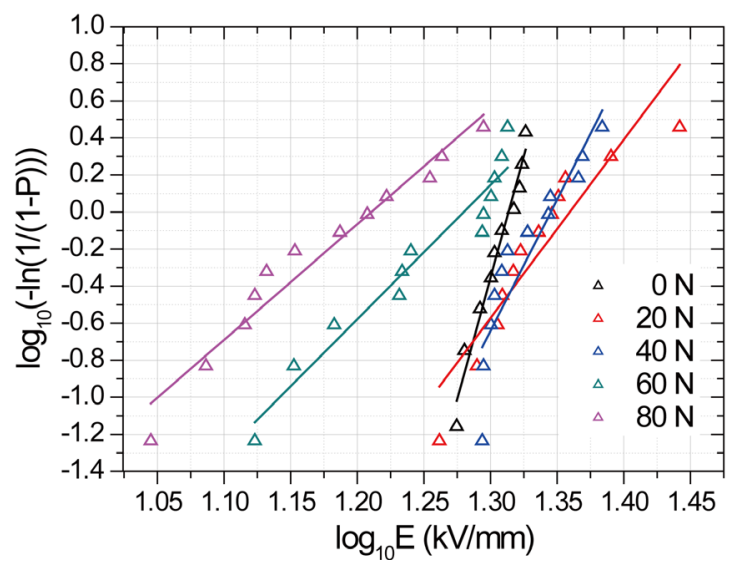

Figure 8. Full results for the dielectric breakdown of prestressed alumina plates ( 0 to $80 \mathrm{~N}, 1$ minute).

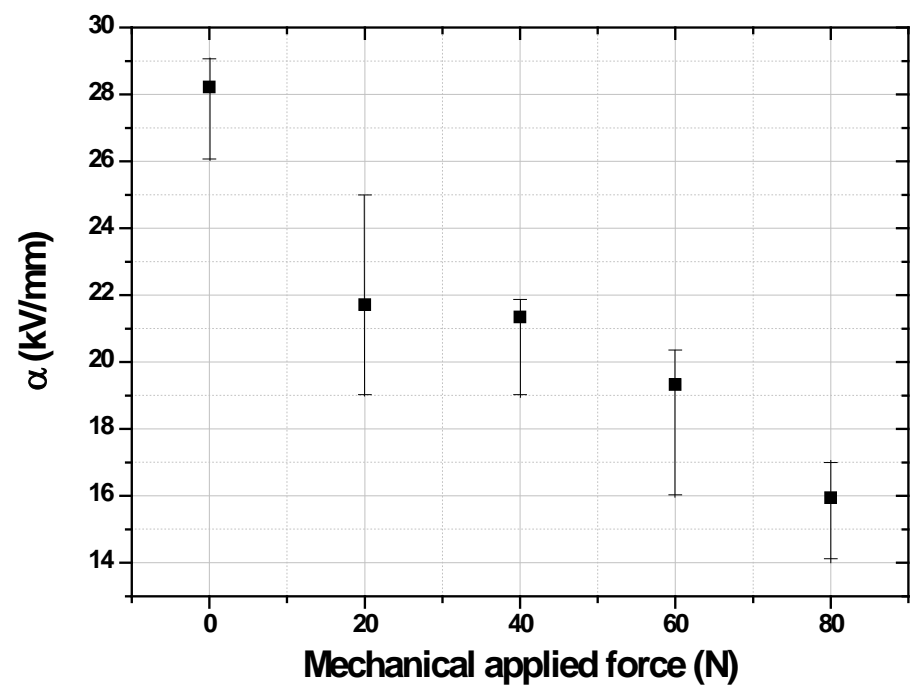

Figure 9. a values for the dielectric breakdown of prestressed alumina plates ( 0 to $80 \mathrm{~N}$, for $\mathrm{t}_{\text {appl }}=1$ minute), error bars correspond to the $90 \%$ confidence intervals.

perfectly align the high voltage tip with the maximum stress region. The felt-tip pen is 1 $\mathrm{mm}$ thick and the exact width of the stressed region is for the moment unknown. Another reason for the large dispersion of the $\mathrm{E}_{\mathrm{br}}$ values could arise from the nature of the crack propagation itself, especially if the cracks are not homogeneously distributed along the stressed plane.

The results of dielectric breakdown of alumina show higher dielectric strength for lower mechanical prestress.

Assuming a constant extension speed, the evolution of the dielectric strength was correlated with the evolution of cracks at prestressing, what supports the contribution of mechanical properties to dielectric breakdown phenomena in alumina. This could be explained by the fact that the dielectric failure mechanism of the alumina-based ceramic is strongly associated with the propagation of cracks, and a change in behavior of the 
latter will influence the dielectric strength.

We should consider that for application purposes, the alumina (or any other ceramic mentioned in section 1) is a part of a complex assembly with other materials, with a metal being in immediate ontact with the substrate assembly. While there are some studies that highlight the importance of the initial mechanical properties of the ceramic within the substrate assembly [24], the data presented here indicates that the other processing parameters of the alumina could be relevant. This could indicate the need to take into account the mechanical history of the ceramic as having an impact on the dielectric strength value.

\section{Conclusion}

The dielectric breakdown of the studied alumina depends on the value of the mechanical prestress created by a 3-point bending test. Despite the large dispersion of the results, a global tendency satisfies the currently used model of electromechanical breakdown, where the defect size impacts the short-term dielectric strength of alumina. Higher values of mechanical prestress induce a decrease in the $\mathrm{E}_{\mathrm{br}}$ values. This could imply that not only the original dielectric properties of the ceramics should be taken into account for dimensioning purposes, but also their full mechanical history.

\section{Acknowledgements}

The authors acknowledge the assistance from E. Duhayon for providing access to the mechanical test bench. Z. Jouini thanks the French Ministry of Research and Higher Education for its financial support through a doctoral studies grant.

\section{References}

[1] Chasserio, N., Guillemet-Fritsch, S., Lebey, T. and Dagdag, S. (2009) Ceramic Substrates for High-Temperature Electronic Integration. Journal of Electronic Materials, 38, 164-174. http://dx.doi.org/10.1007/s11664-008-0571-8

[2] Diaham, S., Locatelli, M.-L. and Valdez-Nava, Z. (2011) Dielectrics for High Temperature $\mathrm{SiC}$ Device Insulation: Review of New Polymeric and Ceramic Materials. In: Mukherjee, M., Ed., Silicon Carbide-Materials, Processing and Applications in Electronics Devices, Chapter 17 in, Intech, 409-430. http://dx.doi.org/10.5772/24397

[3] Benmansour, A., Azzopardi, S., Martin, J.-C. and Woirgard, E. (2006) Failure Mechanism of Trench IGBT under Short-Circuit after Turn-Off. Microelectronics and Reliability, 46, 1778-1783. http://dx.doi.org/10.1016/j.microrel.2006.07.059

[4] Azzopardi, S. (1998) Contribution à la caractérisation et à a modélisation de l'IGBT en vue d'une hybridation destinée à fonctionner à température élevée pour le véhicule électrique. PhD Thesis, Bordeaux 1 University, Bordeaux Cedex.

[5] Ciappa, M. (2002) Selected Failure Mechanisms of Modern Power Modules. Microelectronics Reliability, 42, 653-667. http://dx.doi.org/10.1016/S0026-2714(02)00042-2

[6] Coquery, G., Lefranc, G., Litcht, T., Lallemand, R., Seliger, N. and Berg, H. (2003) High Temperature Reliability on Automotive Power Modules verified by Power Cycling Tests up to $150^{\circ} \mathrm{C}$. Microelectronics reliability, $43,1871-1876$. http://dx.doi.org/10.1016/S0026-2714(03)00318-4 
[7] Lefranc, G., Licht, T., Schults, H.J., Beinert, R. and Mitic, G. (2000) Reliability Testing of High Power Multi-Chip IGBT Modules. Microelectronics Reliability, 40, 1659-1663. http://dx.doi.org/10.1016/S0026-2714(00)00185-2

[8] Ramminger, S., Turkes, P. and Wachutka, G. (1998) Crack Mechanism in Wire Bonding Joints. Microelectronics Reliability, 38, 1301-1305. http://dx.doi.org/10.1016/S0026-2714(98)00141-3

[9] Woirgard, E. (1992) Contribution à l'étude d'une intégration hybride adaptée à l'électronique automobile. PhD Thesis, Bordeaux 1 University, Bordeaux Cedex.

[10] Herr, E., Frey, T., Schlegel, R., Stuck, A., Zehringer, R. and Deleonibus, S. (1997) Substrate-to-Base Solder Joint Reliability in High Power IGBT Modules. Microelectronics and Reliability, 37, 1719-1722. http://dx.doi.org/10.1016/S0026-2714(97)00147-9

[11] Khatir, Z. and Lefebvre, S. (2000) Thermal Analysis of High Power IGBT Modules. Proceedings of the 12 th International Symposium on Power Semiconductor Devices and ICs Proceedings, Toulouse, 22-25 May 2000, 271-274. http://dx.doi.org/10.1109/ispsd.2000.856823

[12] Rizzi, M. (2008) Contribution à l'étude de la fiabilité des modules de puissance pour application automobile. PhD Thesis, Bordeaux 1 University, Bordeaux Cedex.

[13] Fabian, J.H., Hartmann, S. and Hamidi, A. (2005) Analysis of Insulation Failure Modes in High Power IGBT Modules. 40 th IAS Annual Meeting Conference Record of the 2005 Industry Applications Conference, Hong Kong, 2-6 October 2005, 799-805.

[14] Breit, F., Malec, D. and Lebey, T. (2002) Investigations on DC Conductivity and Space Charge in Silicone Gel. 2002 Annual Report Conference on Electrical Insulation and Dielectric Phenomena,USA, 20-24 October 2002, 48-51. http://dx.doi.org/10.1109/CEIDP.2002.1048733

[15] Lebey, T., Malec, D., Bley, V. and Breit, F. (2003) Contribution to the Dimensioning of The Different Insulating Materials Used in High Voltage Power Electronics Module Manufacturing. The 5 th International Conference on Power Electronics and Drive Systems, Singapore,17-20 November 2003, 55-59.

[16] Malec, D., Dinculescu, S. and Lebey, T. (2000) Aging of Ceramic Materials in Power Electronic Substrates. 2000 Annual Report Conference on Electrical Insulation and Dielectric Phenomena, Victoria, 15-18 October 2000, 604-607. http://dx.doi.org/10.1109/CEIDP.2000.884032

[17] Decup, M., Malec, D. and Bley, V. (2009) Impact of a Surface Laser Treatment on the Dielectric Strength of $\alpha$-Alumina. Journal of Applied Physics, 106, Article ID: 094103. http://dx.doi.org/10.1063/1.3253731

[18] Yoshimura, M. and Bowen, H.K. (1981) Electrical Breakdown Strength of Alumina at High Temperatures. Journal of the American Ceramic Society, 64, 404-410. http://dx.doi.org/10.1111/j.1151-2916.1981.tb09879.x

[19] Carabajar, S., Olagnon, C., Fantozzi, G. and Le Gressus, C. (1995) Relations between Electrical Breakdown Field and Mechanical Properties of Ceramics. 1995 Annual Report Conference on Electrical Insulation and Dielectric Phenomena, Virginia Beach, 22-25 October 1995, 278-281. http://dx.doi.org/10.1109/CEIDP.1995.483717

[20] Fothergill, J.C. (1991) Filamentary Electromechanical Breakdown. IEEE Transactions on Electrical Insulation, 26, 1124-1129. http://dx.doi.org/10.1109/14.108149

[21] Zeller, H.R. and Schneider, W.R. (1984) Electrofracture Mechanics of Dielectric Aging. Journal of Applied Physics, 56, 455-459. http://dx.doi.org/10.1063/1.333931

[22] Malec, D., Bley, V., Talbi, F. and Lalam, F. (2010) Contribution to the Understanding of the 
Relationship between Mechanical and Dielectric Strengths of Alumina. Journal of the European Ceramic Society, 30, 3117-3123.

http://dx.doi.org/10.1016/j.jeurceramsoc.2010.07.024

[23] Touzin, M., Goeuriot, D., Fitting, H.J., Guerret-Piécourt, C., Juvé, D. and Tréheux, D. (2007) Relationships between Dielectric Breakdown Resistance and Charge Transport in Alumina Materials-Effects of the Microstructure. Journal of the European Ceramic Society, 27, 1193-1197. http://dx.doi.org/10.1016/j.jeurceramsoc.2006.05.047

[24] Dupont, L., Zoubir, K., Lefebvre, S. and Bontemps, S. (2006) Effects of Metallization Thickness of Ceramic Substrates on the Reliability of Power Assemblies under High Temperature Cycling. Microelectronics Reliability, 46, 1766-1771.

http://dx.doi.org/10.1016/j.microrel.2006.07.057

Submit or recommend next manuscript to SCIRP and we will provide best service for you:

Accepting pre-submission inquiries through Email, Facebook, LinkedIn, Twitter, etc. A wide selection of journals (inclusive of 9 subjects, more than 200 journals)

Providing 24-hour high-quality service

User-friendly online submission system

Fair and swift peer-review system

Efficient typesetting and proofreading procedure

Display of the result of downloads and visits, as well as the number of cited articles

Maximum dissemination of your research work

Submit your manuscript at: http://papersubmission.scirp.org/ 